Article

\title{
An Interactive Planning Support Tool for Addressing Social Acceptance of Renewable Energy Projects in The Netherlands
}

\author{
Johannes Flacke * (1) and Cheryl de Boer \\ Faculty of Geo-Information Science and Earth Observation (ITC), University of Twente, P.O. Box 6, \\ 7500 AE Enschede, The Netherlands; c.deboer@utwente.nl \\ * Correspondence: j.flacke@utwente.nl; Tel.: +31-53-4874-381
}

Received: 17 July 2017; Accepted: 13 October 2017; Published: 19 October 2017

\begin{abstract}
The implementation of renewable energy policies is lagging behind in The Netherlands. While several Dutch cities have ambitious goals for reducing greenhouse gas (GHG) emissions, the implementation of renewable energy projects has been rather slow. The main reasons for this are the limited institutional capacities of local decision-makers, low levels of social acceptance of renewable-energy technologies, and limited opportunities for engagement of communities in decision-making processes. In order to address these issues we have developed an interactive planning support tool named COLLAGE for stakeholder participation in local renewable-energy planning. The goal of this paper is to analyze whether the COLLAGE tool helps to increase community engagement in renewable-energy projects and planning by increasing awareness and addressing social learning issues related to renewable-energy options. We tested the tool in a series of workshops with stakeholders and citizens from the city of Enschede, The Netherlands. The workshop results show that the tool helped involve stakeholders and communities in deciding where to locate renewable-energy facilities. It increased community members' awareness of the benefits of and requirements for renewable energy by disclosing the spatial consequences of overall municipal goals. We conclude that the COLLAGE tool can be an important building block towards new local energy governance.
\end{abstract}

Keywords: renewable energy; social acceptance; energy governance; interactive mapping tools; maptable

\section{Introduction}

Renewable energy is an important cornerstone of global and national climate change policies, such as the Paris Agreement [1] and the EU roadmap towards a competitive, low-carbon economy [2], but its implementation is lagging behind in many European countries, including The Netherlands. While several Dutch cities have developed ambitious goals for reducing greenhouse gas (GHG) emissions, many of them aiming to become carbon-neutral within the next 20 to 35 years [3], the implementation of renewable-energy systems such as wind turbines or solar farms has been very slow in The Netherlands compared with other European countries. In 2014, the share of energy from renewable-energy technology was only $4.4 \%$ of the gross inland energy consumption in The Netherlands, while the average renewable-energy share of the EU-28 countries accounted for $12.5 \%$ of the gross inland energy consumption in 2014, with countries such as Austria (30\%) or Sweden (35\%) having the highest share among the EU countries [4].

Scholars have identified two main reasons for the low development of renewable-energy projects: (a) limited institutional capacities of local decision-makers with respect to the implementation of renewable-energy policies, particularly with respect to wind power [5], due to an emphasis 
on centralized policy-making and an underestimation of issues of spatial and environmental planning; and (b) strong opposition from local communities and individual citizens towards the implementation of large-scale renewable-energy projects, often referred to as the NIMBY ("Not In My Backyard") phenomenon [6]. Wuestenhagen et al. [7] capture both barriers within the concept of social acceptance of renewable, particularly wind-energy innovations, which includes the three interdependent dimensions of socio-political acceptance, community acceptance, and market acceptance. Socio-political acceptance refers to the public acceptance of renewable-energy technologies and policies by key stakeholders and policy actors. Community acceptance, which is typically understood as the NIMBY phenomenon, refers to the specific acceptance of siting decisions and renewable-energy projects by local stakeholders, particularly residents and local authorities. Market acceptance, finally, explains the adoption of innovative products by consumers through a communication process between individual adopters and their environment. Sovacool and Lakshmi Ratan [8] have analyzed how the acceptance of wind- and solar-energy projects depends upon the prevalence of nine interrelated factors: (1) strong institutional capacity; (2) political commitment; (3) favorable legal and regulatory frameworks; (4) competitive installation and/or production costs; (5) mechanisms for information-sharing and feedback; (6) access to financing; (7) prolific community and/or individual ownership and use; (8) participatory project siting; and (9) recognition of externalities or positive public image.

Devine Wright et al. [9] claim that research of social acceptance of renewable energy is skewed towards understanding resistance to technology implementation by reference to the NIMBY concept. While the NIMBY explanation is often seen by policy-makers and investors and as the main obstacle to renewable-energy implementation [10], Breukers and Wolsink [11] argue, that the limited opportunities for communities' engagement in the decision-making process relating to the siting of renewable-energy projects is also part of the problem. Particular local authorities, having a major role in the energy transition due to their existing geographical and political proximity to individual, household and community-level activities and practices [12,13], are important actors in this context. However, public participation and community engagement in the development of renewable-energy projects are often limited to one-directional information campaigns with websites or leaflets in order to convince the public of the advantages of particular renewable-energy locations rather than allowing for an open discussion, e.g., within a public meeting where opponents would have the opportunity to collectively express emotional antagonism and influence other citizens [10]. The close relationship between NIMBYism and limited public engagement is described by Devine Wright as a "rather destructive, self-fulfilling cycle [ ... ] in which local opposition is interpreted by developers and policy-makers as evidence of NIMBYism, which leads to engagement practices whose main goal is to allay NIMBY responses by limiting engagement opportunities" [10] (p. 22).

Breaking such a cycle requires new ways of thinking and practising public engagement that better connects policy-making with local areas directly affected by specific projects. In contrast to traditional, centralized energy systems that are mainly regulated by national and/or state/provincial governments, the implementation of renewable-energy projects requires strong engagement from local communities [14]. Citizens need to understand the relationship between local actions for renewable energy and global or national climate change goals [12]. This is where the involvement of local authorities is crucial, especially in terms of emphasizing the relevance of a collective endeavor. Therefore, a more inclusive process that involves local residents in the development of local renewable-energy policies as well as in the concrete siting of renewable-energy projects in specific localities is needed.

However, it needs to be acknowledged that the development of renewable-energy policies and projects should be understood as a typical wicked problem [15], which is generally seen as "complex, open-ended, and intractable, while both the nature of the 'problem' and the preferred 'solution' are strongly contested" [16] (p. 101) among stakeholders. The choice between different types of renewable energy, such as wind, solar, biogas, etc., all of them having various positive as well as negative impacts, 
leads to complex trade-offs when it comes to decision-making, which are exacerbated by various mental models, perceptions, and preferences of the various stakeholders involved. Scholars need to examine such types of wicked problems "through a panoramic social lens rather than a scientific microscope, and working with it in an open and heuristic process of collective learning, exploration, and experimentation" [17] (p. 2). In other words, engaging with local stakeholders and communities from the very early planning phases onwards is the best way to address and mitigate the wickedness of the development of renewable-energy strategies and projects.

In order to address the issues discussed above, we have developed an interactive planning support tool for stakeholders' and citizens' participation in local renewable-energy planning that we named COLLAGE (Collaborative Location and Allocation Gaming Environment). Implemented on a digital maptable, the COLLAGE tool encourages stakeholders to discuss jointly where to allocate what kind of renewable-energy systems (wind, solar) within the municipal boundaries. While doing so, the model calculates various impacts, benefits and trade-offs of the current allocation and thus allows stakeholders to reflect immediately on the different options. The goal of the COLLAGE tool is to stimulate and substantiate stakeholder discussions towards consensual options and locations, and to raise awareness and facilitate social learning of stakeholders and local communities in relation to the different renewable-energy options. Social learning is understood in this context as a process of iterative reflection that occurs when participants share their experiences, ideas and environments with others during a group activity [18].

In the paper we present the application of the COLLAGE tool in stakeholder workshops in the city of Enschede, The Netherlands. The goal of the paper is to analyze whether and how the COLLAGE tool helps to increase community engagement in renewable-energy projects and planning by increasing awareness and addressing social learning issues relating to renewable-energy options. In Section 2, we describe the framework and functioning of the COLLAGE tool in detail. Section 3 presents details of the case study, the adoption of the COLLAGE tool for the specific case study, and the workshops we conducted. In Section 4, we analyze the results of the mapping sessions during the workshops and compare these to the perceptions of the participants towards renewable energy. We further analyze particular lessons learned by the participants during the workshops and evidence of awareness-raising and social learning. In the final section, we discuss how the COLLAGE tool can be used to support the introduction of new forms of local energy governance [19], that gives local governments and communities a stronger role in the future governance of energy systems.

\section{The COLLAGE Tool}

The COLLAGE tool is a stakeholder-oriented interactive planning support tool implemented on a maptable. A maptable is a large-scale horizontal interactive display that shows digital content in terms of maps and allows users to interact with the content via touching and gestures (Figure 1). Often a second screen is attached to it that is used to either display a 3D scene of the 2D map shown on the maptable or the results and outcomes from the interactive mapping sessions. Due to its horizontal installation, up to 6 participants can gather around the table and interact with the digital content on the interactive screen and with fellow participants [20]. The current version of the COLLAGE tool is implemented in CommunityViz Scenario 360 software [21], an extension to ArcGIS.

Such interactive Planning Support Systems (PSS) have been applied and tested in research, focusing on improving stakeholder participation in planning processes, for the last couple of years [22]. They are seen as particularly useful for initiating and strengthening interaction and collaboration between participants, e.g., stakeholders and citizens. Pelzer et al. [23] researched the added values such interactive PSS provide to urban planning processes. Shrestha et al. [24] showed how such interactive PSS tools support stakeholders in expressing their views, understanding other people's views, and coming to a consensus or a shared understanding of a problem situation. While most studies of the added values of such interactive, maptable-based PSSs for supporting planning processes focus on the participation of domain experts and other stakeholders, the use and usability of such 
systems within decision-making processes involving laypersons or, so to speak, "normal" citizens, is hardly explored.

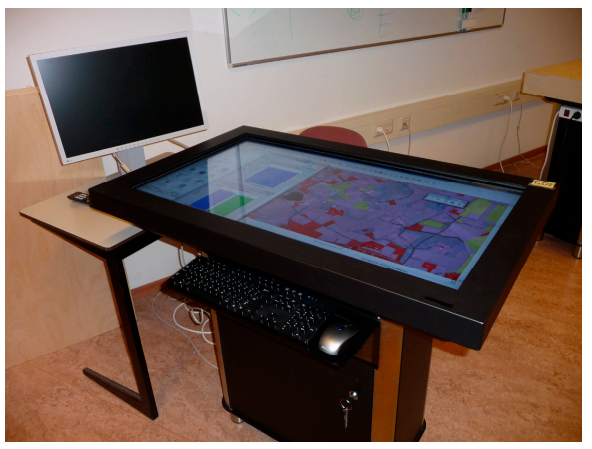

(a)

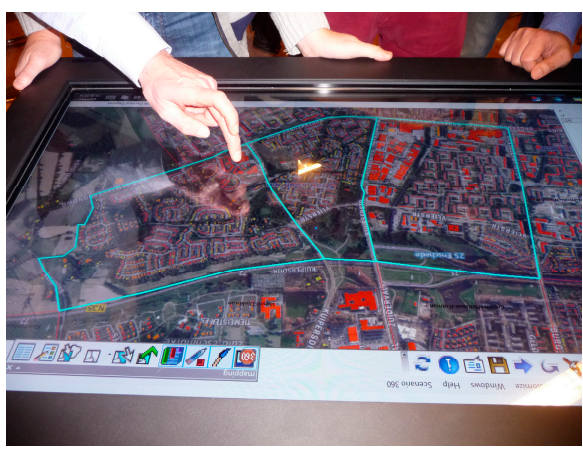

(b)

Figure 1. The interactive maptable: (a) the entire maptable setup including a second screen; (b) participants interacting with the maptable during a workshop session.

The current COLLAGE tool focuses on wind and solar energy technologies, the latter being sub-divided into solar parks, i.e., a large number of solar panels typically mounted on the ground, and solar panels on rooftops. Other renewable-energy technologies such as geothermic energy or biogas installations will be included in future versions of the model. The COLLAGE tool includes several sets of spatial data, such as building footprints, land use and administrative boundaries (Table 1) that were used to generate the layers of spatial information that are shown on the maptable (Table 2) for informing the participants during the participatory mapping process.

Table 1. Complete list of data sets used.

\begin{tabular}{cl}
\hline Data Set & Source \\
\hline Municipal boundaries & Municipality of Enschede \\
Land use & Municipality of Enschede \\
Sun map (building footprints) & Municipality of Enschede \\
Ecologically sensitive areas & Municipality of Enschede \\
Built-up areas & Municipality of Enschede \\
High voltage lines & Municipality of Enschede \\
Canals & Municipality of Enschede \\
Railroad tracks & Municipality of Enschede \\
Gas pipes & Municipality of Enschede \\
\hline
\end{tabular}

The data layer rooftop suitability shows the suitability of each single building for solar panels in five categories from not suitable at all to very suitable. This categorization is taken from the so-called "sun map" (in Dutch: zonnekaart) [25], a classification of rooftops according to their suitability for setting up solar panels that is available for the whole of The Netherlands. The classification of each roof is based on the solar radiation at that location, the angle of the roof and its exposure/orientation.

Table 2. Data layers shown on the maptable.

\begin{tabular}{lll}
\hline Layers of Information & Description/Purpose & Source \\
\hline municipal boundaries & district and neighborhood boundaries & Municipality of Enschede \\
\hline land use & main land use categories & Municipality of Enschede \\
\hline rooftop suitability & suitability for solar panels on roofs & sun map [25] \\
\hline number of solar panels & Max no. of solar panels possible per rooftop & sun map [25] \\
\hline solar park suitability & area suitable for solar parks & derived from base data \\
\hline suitable wind area & area suitable or wind energy installations & derived from base data \\
\hline aerial photograph & webservice, for orientation & Dutch National SDI (PDOK) [26] \\
\hline street names, names of regions and districts & webservice, for orientation & Dutch National SDI (PDOK) [27] \\
\hline
\end{tabular}


The layer suitable wind area demarcates areas in which wind turbines are allowed according to Dutch planning law. The criteria used for demarcating the suitable wind area are given in Table 3. Setting up of solar parks is allowed in agricultural areas and green areas outside the urban core, except those areas that are ecologically sensitive, as well as within industrial areas.

Table 3. Criteria applied for the demarcation of the suitable wind area.

\begin{tabular}{cc}
\hline Data Set & Criteria \\
\hline built-up urban core area & $400 \mathrm{~m}$ distance \\
residential buildings outside the urban core & $400 \mathrm{~m}$ distance \\
ecologically sensitive areas & excluded \\
high voltage lines & $245 \mathrm{~m}$ distance \\
canals & $50 \mathrm{~m}$ distance \\
railroad tracks & $100 \mathrm{~m}$ distance \\
gas pipes & $245 \mathrm{~m}$ distance \\
\hline
\end{tabular}

Functions for navigating (zoom in/out, pan, etc.) allow the users to maneuver interactively through the area. These functions are intuitive to use and can be learned easily by the stakeholders at the beginning of a workshop. While the stakeholders navigate in the map they can allocate different types of renewable-energy sources by selecting a priori defined types of renewable energy and drawing them on the map. While mapping these renewable-energy features, various outcome indicators of impacts, costs or benefits are calculated and visualized in charts on the second screen (Figure 2). In the current version of the model, the following indicators are calculated: total renewable-energy production in Megawatt hours per year (MWh/a); total and per renewable energy type (wind, solar parks, solar rooftops, Figure 2a); renewable-energy production from solar rooftops in MWh/a, divided into residential and non-residential; and the energy mix in percentage of total renewable energy produced (Figure 2 b). In both bar charts, the respective goals to be achieved during the workshop are also indicated.

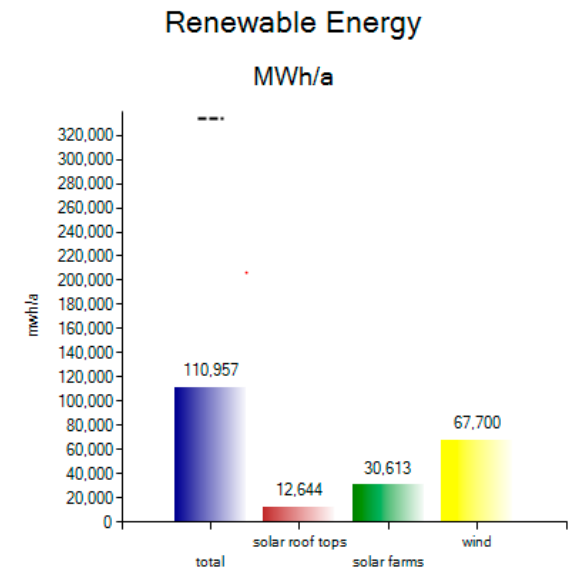

(a)

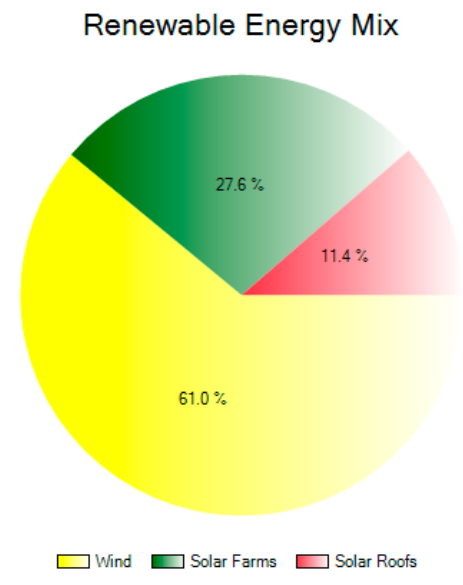

(b)

Figure 2. Charts visualizing the outcome indicators of the mapping sessions: (a) bar chart showing total renewable energy in MWh per type of renewable energy resulting from the current allocations; (b) the resulting mix of renewable energy.

\section{Enschede Case Study}

\subsection{Renewable-Energy Policies in the City of Enschede, The Netherlands}

Enschede is a medium-sized city with around 160,000 inhabitants located on the eastern border of The Netherlands. On 20 June 2014, the city officially became a Covenant of Mayors signatory by 
signing up to the European initiative for local and regional authorities aiming to exceed the Europe 2020 goal of reducing carbon emissions by $20 \%$ by 2020 [28]. In 2016, only $1.2 \%$ of the total electric energy consumption in Enschede was renewable produced from solar energy [29]. However, this share has increased significantly over the years, starting from $0.1 \%$ in 2012 [29].

An evaluation of the potential for renewable energy for Enschede finds that the city has very little space available for the development of renewable energy compared with other Dutch cities [30]. Areas for the installation of wind turbines are rather limited due to the required distance from residential areas and other offsets, as listed in Table 3 (Figure 3). Moreover, due to the airport area in the north of Enschede, only wind turbines up to a tip height of $140 \mathrm{~m}$ are allowed in some of the areas suitable for wind. On the other hand, the potential for development of solar farms is significant. Based on this study, the goals of the city of Enschede with respect to the implementation of renewable energy are to have a share of at least $12 \%$ by the year 2030 and at least $27 \%$ by 2050 of the projected energy need coming from renewable energy produced with the municipal boundaries [28]. This is not a very ambitious goal, but is based on an analysis of what is technically achievable. According to the report, this goal needs to be accompanied by a certain amount of energy saving in order to achieve a reasonable CO2-reduction [28].

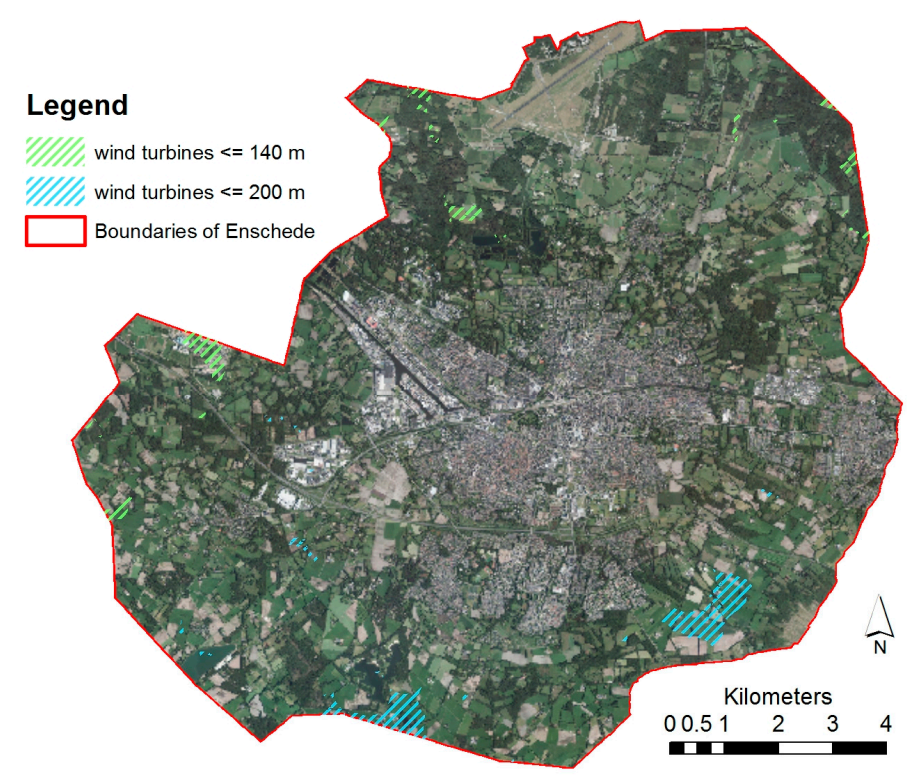

Figure 3. Area suitable for wind turbines in the city of Enschede.

Between October 2016 and March 2017, the city conducted the Enschede wekt op (Enschede wakes up) campaign [31]. The main aims of the campaign were to inform citizens of the local goals for renewable energy, the different forms of renewable energy that could be implemented in order to achieve these goals, and to sensitize and raise popular awareness in relation to these issues and projects. In addition to the information provided via the project website, the campaign conducted various activities and events, such as a town-hall meeting and various public brainstorming sessions. On the website, five scenarios describing potential locations for renewable energy were presented, as developed in advance by the municipality. The results and outcomes of the entire campaign are summarized in a final report [32]. The participatory workshops using the COLLAGE tool were also part of the campaign. Participants could register for the COLLAGE workshops via the project website.

\subsection{The COLLAGE Tool for Enschede}

The specific roll out of the COLLAGE model and tool for the Enschede workshops was developed in close cooperation with the municipality. In the Enschede COLLAGE model participants could 
choose between a total of seven different options for renewable wind and solar energy, all having a different intensity and representing different levels of visual and environmental impacts (Table 4). Solar panels on roofs could be assigned in three different intensities of $100 \%, 60 \%$ and $30 \%$ coverage of the rooftop. Intensive solar parks represent a land use exclusively for solar energy production, while extensive solar parks allow a combined land use of solar energy production and, for example, meadow. The two different types of wind turbines of $193 \mathrm{~m}$ and $134 \mathrm{~m}$ tip height represent the wind turbine models most commonly used in the area and therefore most likely to be known to the participants. The different renewable-energy types and options and their respective energy productivity used for calculating the outcome indicators (see above) are given in Table 4. The outcome indicator total renewable energy is calculated based on the total number of wind turbines times their specific energy productivity; plus the total area of solar parks times their specific energy productivity; plus the total number of solar panels of all selected buildings times specific energy productivity divided by the selected options $(100 \%, 60 \%, 30 \%)$.

Table 4. Renewable-energy options in the COLLAGE tool for Enschede.

\begin{tabular}{ccc}
\hline Type of Renewable Energy & Option & Energy Productivity \\
\hline solar panels on roofs & $100 \%^{1}$ & $240 \mathrm{w}$ per panel \\
& $60 \%^{1}$ & $240 \mathrm{w}$ per panel \\
solar parks & $30 \%^{1}$ & $240 \mathrm{w}$ per panel \\
& intensive & $835 \mathrm{MWh}$ per ha \\
wind turbines & extensive & $500 \mathrm{MWh}$ per ha \\
& $193 \mathrm{~m}$ turbine & $8300 \mathrm{MWh}$ per turbine \\
& $134 \mathrm{~m}$ turbine & $4800 \mathrm{MWh}$ per turbine \\
\hline \multicolumn{3}{c}{$\%$} \\
\end{tabular}

\subsection{The Enschede COLLAGE Workshops}

Three stakeholder workshops using the COLLAGE tool were conducted in Enschede between November 2016 and January 2017, hosting in total 35 participants. All three workshops addressed different target groups within the citizenry. The first workshop, hosting in total 15 participants, was an open workshop to which all citizens were invited. The second workshop, with 12 participants, focused particularly on citizens that were already somewhat engaged in local energy and/or sustainability initiatives in Enschede. The third workshop involved eight local policy-makers from the different parties represented on the city council of Enschede. The participants of the first workshop had signed up for it via the project website. Participants for the second workshop were recruited using existing contacts to local energy and sustainability groups. For the third workshop, we invited the members of the city council. The first workshop included three groups of five participants each, whilst the other two workshops both included two parallel groups. Each group worked on one maptable, i.e., in total, results from seven groups of stakeholders were used in this analysis.

All workshops were designed for a duration of approximately $2.5 \mathrm{~h}$. During the workshops, the stakeholders were asked to work on a couple of tasks in various sessions. The sequence of workshop sessions and tasks was a priori designed and tested in a series of test workshops. In all sessions, the groups were asked to discuss potential locations for the installation of renewable energy in Enschede, and subsequently to allocate the respective energy options as available in the model (see above). For orientation of the participants the system displayed the goals in terms of renewable-energy production to be achieved during the single sessions based on the $12 \%$ goal of renewable energy for Enschede.

After an introduction to the Enschede wekt op campaign, the workshops' goals and the renewable-energy context in the city, the participants were asked to complete a short exercise on the maptable in order to understand and learn the functioning of the COLLAGE tool. After that, the participants worked in two subsequent sessions of approx. $30 \mathrm{~min}$ on the allocation of renewable 
energy. The first session focused on the allocation of solar panels on rooftops in the urban built-up core of Enschede. Therefore, the participants were asked to select one neighborhood that they were already familiar with. After selection, the system displayed the goal in terms of renewable energy based on the overall goals of the city of Enschede broken down to the share of energy consumption in that neighborhood in 2015, i.e., $12 \%$ of the consumption of electricity in that neighborhood in 2015.

The second session focused on the allocation of solar parks and wind turbines on the outskirts and in rural area of Enschede, thus covering the entire area of Enschede. The goal-setting for this session was in total 330,000 MWh renewable energy for wind and solar. This represented $12 \%$ of the total energy consumption in Enschede in 2015, minus the share that is potentially to be derived from biogas, as this source of renewable energy is also relevant for Enschede but is not yet included in the model. Towards the end of the workshop, the groups reported the results of the sessions, and the main issues discussed, back to the plenary.

All mapping sessions were supported by a moderator and a chauffeur on each maptable, which has proven to be useful when carrying out interactive mapping sessions on a maptable [33]. The moderator facilitates and structures the mapping sessions by guiding the process, asking the right questions and making sure that all members of the group participate actively. The chauffeur is responsible for supporting the mapping when technical issues occur with respect to the table, helping with the handling of the socio-technical tool.

In order to analyze the outcomes of the workshops and the usability and applicability of the tool, we employed a combination of different data collection and analytical methods. All participants answered a questionnaire including questions on their perception of renewable energy, the usability of the tool, and some socio-demographic factors at the end of the workshop. The questionnaire (Appendix A) included 5-point Likert scales and also open-ended questions. For all mapping sessions, screen and voice recording was implemented in order to capture the interactions of the participants with the tool together with their arguments and reasoning. Protocols from workshop observations prepared by a workshop observer were used to support findings from the analysis of the screen captures and voice recordings. SPSS (version 24) was used to analyze the results from the questionnaire. Listening to the recordings of the mapping sessions, we transcribed the main issues mentioned by the various participants.

\section{Results}

This report of the results from the Enschede COLLAGE workshops starts with the perceptions and preferences of the participants towards renewable energy. In considering these factors, we distinguish between the participants who had already installed some type of renewable energy at their own home and those who had not, assuming that participants belonging to the first group have a more positive attitude, in general, towards renewable energy. We then report the results and outcomes of the mapping sessions and conclude with a discussion of the lessons learned from the mapping sessions.

\subsection{Participants' Profile and Perception of Renewable Energy}

The profile of the workshop participants and their perceptions and preferences towards renewable energy is based on a total of 35 questionnaires completed by the participants in the three workshops conducted between November 2016 and January 2017. Of the 35 respondents, 91\% (32 respondents) lived in their own house in Enschede and only two lived in a rented house (1 participant did not provide an answer). A majority of 13 respondents (37\%) lived in district south, followed by 7 participants from Centrum and 6 from Oost, 4 participants each from districts Noord and West, and one participant did not live in Enschede. The vast majority of participants were aged 31-50 years (12 respondents) or 51 to 65 years (10 participants); 2 participants were younger than 18, 5 between 18 and 30 years old, and 6 above 65 years. The self-reported average monthly household income of more than $50 \%$ of the participants was between $€ 3000$ and $€ 3999$ (7 respondents) or higher than $€ 4000$ (12 participants). 
Only two participants reported an average monthly household income of less than $€ 2000$ and five had an income of $€ 2000-2999$. Nine respondents did not provide details on their income situation.

The sample of Enschede citizens that participated in the workshops shows a reasonable distribution in terms of age as well as place of residence, as all age groups and districts of Enschede are represented. On the other hand, the sample is rather skewed towards citizens with a higher average income and home owners, both items presumably being correlated to one another. In any case, while the sample used in this study does not allow any conclusions in relation to the city as a whole or inferences based on statistical analysis such as correlations, it is broad enough to analyze qualitatively how the work with the COLLAGE tool affects preferences and knowledge about renewable energy.

The majority of participants in the workshops showed a generally positive attitude towards renewable energy. Almost half of the participants (16 respondents, $45 \%$ ) reported that they had some sort of renewable energy installed already, most of them having solar panels on their homes. Regarding the question of what they personally think the share of renewable energy in Enschede in 2030 should be (in steps of $5 \%$ between $0 \%$ and $100 \%$ ), answers varied between $5 \%$ and $100 \%$, with an average value of $33 \%$ and a median of $30 \%$, hence far higher than the target set by the city of Enschede. The range of values shows, on the one hand, the diversity of participants' attitudes towards renewable energy, but on the other hand a generally positive attitude towards renewable energy among the majority of participants.

Regarding the participants' perception of the potential benefits of renewable energy, most participants agreed that renewable energy is a good option for reducing GHG emissions (97\% agreement) and that renewable energy helps secure the energy supply for the future $(82 \%$ agreement). However, the argument that the costs and benefits of renewable energy should be kept local receives the lowest levels of agreement and $42 \%$ disagreement, revealing that the argument for local engagement in the development and management of renewable-energy projects [30] is not shared among the majority of participants. Comparing the group of participants who had already had some type of renewable (mostly solar) energy source installed with the participants who had not, shows similar attitudes towards the pros and cons of renewable energy in both groups (Figure 4). However, those participants who had already personally invested in renewable installations reveal a slightly more positive attitude for all five arguments tested.

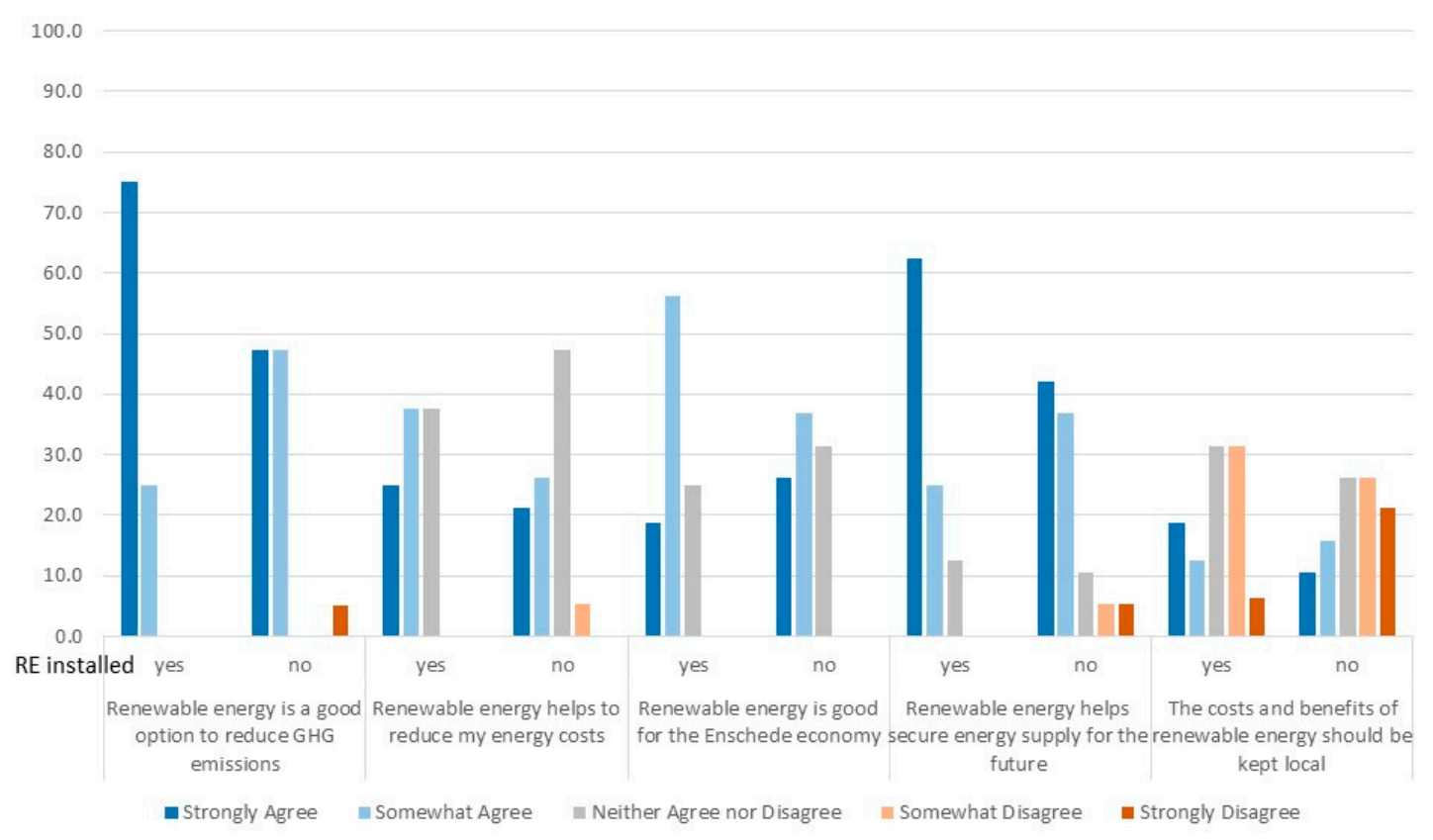

Figure 4. Participants' perception of renewable energy. 
While the participants in the three workshops are very similar in their positive perception of renewable energy as a means of reducing GHG emissions, as well as in their rather reluctant perception of the possibilities of localizing the energy costs and benefits, the policy-makers participating in the third workshop were significantly more positive towards the role of renewable energy for the Enschede economy and for securing the city's future energy supply. Moreover, the participants of the third workshop supported the statement that the costs and benefits of renewable energy should be kept local, while in the other two workshops levels of agreement were significantly lower. We can conclude from this finding that the important issue of costs and (local) benefits from renewable energy is not yet properly addressed in the COLLAGE tool. This might can be improved by adding further outcome indicators such as costs and benefits.

The participants' preference for different renewable-energy options clearly favors solar energy, with a total of $94 \%$ support. Wind energy, on the other hand, is the most debated type of renewable in Enschede. While 51\% of the participants support wind energy to a greater or lesser extent, another $31 \%$ oppose this for Enschede to some extent. Comparing again the group of participants who already have some type of renewable-energy source installed with the participants who have not does not reveal significant differences in perception (Figure 5). Both groups are overwhelmingly positive towards solar energy and show likewise mixed preferences towards wind, with the group not having installations being slightly more positive with a total of $58 \%$ of respondents showing strong or mild agreement compared to $44 \%$ of the other group. The policy-makers from the third workshop were again more open towards wind energy for Enschede, showing $85 \%$ agreement. Interestingly, in contrast to the other two groups, they also see biomass as a potential source of renewable energy for Enschede (85\% support).

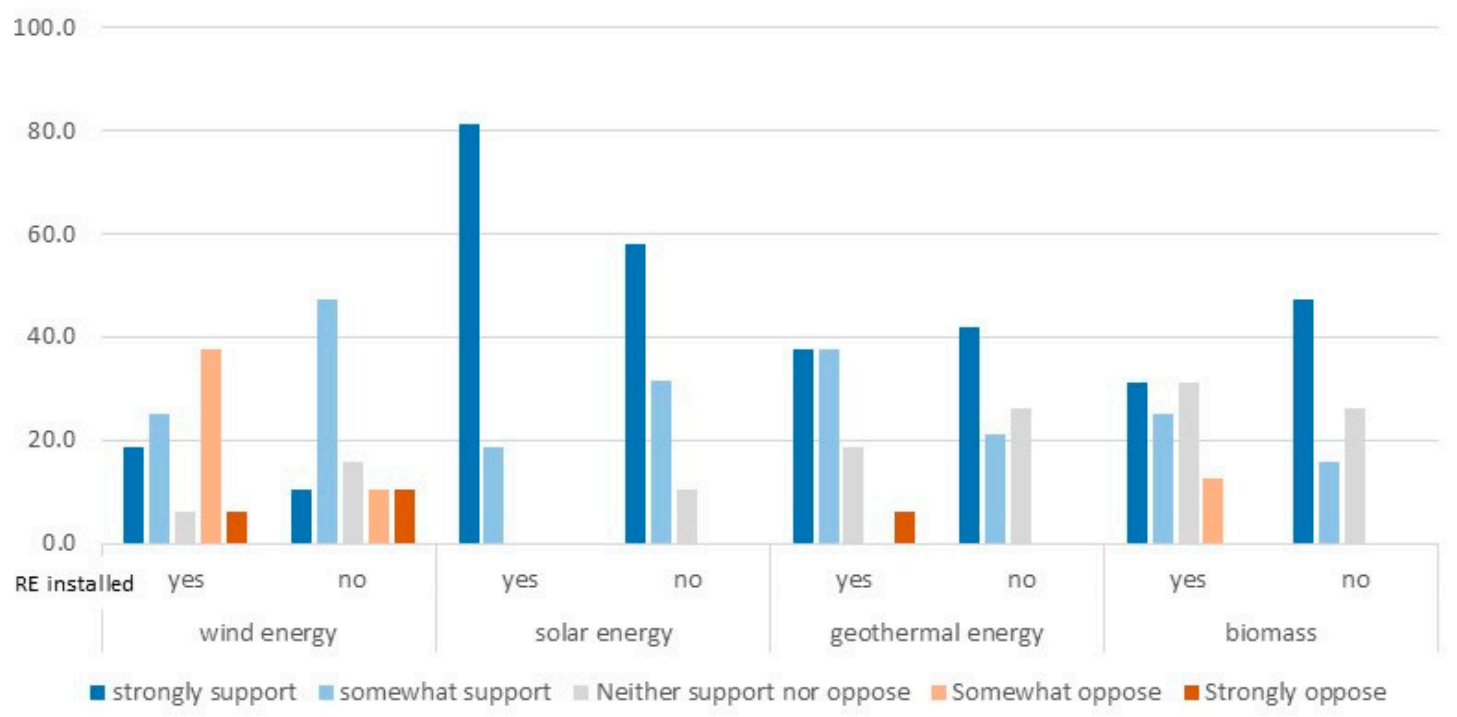

Figure 5. Participants' preference for types of renewable energy.

\subsection{Results of the Collaborative Mapping Sessions}

During the first mapping session, most groups did not achieve the neighborhood goals in terms of renewable-energy implementation by allocating solar panels on suitable roofs. During the second session, focusing on the entire city, all groups managed to achieve the given goal of $330.000 \mathrm{MWh}$ of renewable-energy implementation, mostly via the allocation of several wind turbines and/or large scale solar parks. In relation to this, it needs to be mentioned that during the mapping sessions various groups focused during the second session more on achieving the given goals rather than on an eventually conflicting discussion of potential locations, thereby limiting the relevance of the results as an input to spatial planning of renewable-energy projects. On the other hand, several groups 
acknowledged during the mapping sessions that a mix of various renewable-energy sources was needed for Enschede in order to achieve the goals set, thereby achieving the goal of social learning about renewable energy for Enschede during group activities.

Several groups identified similar locations for wind turbines and solar parks. Areas suitable for solar farms preferred by most groups were the green areas along the highway (A35) that cuts through Enschede in a west-east direction, the abandoned airport area in the north, and the Usseler Ess, a highly contested area on the south-west border of the built-up core that is owned by the municipality and had already been proposed as a solar park. This shows a high level of agreement between the participants in terms of locations for solar parks.

The choice of locations for wind turbines was limited due to the small area suitable for wind turbines in any event, so the allocations of the separate groups were rather similar in this area as well. In general, the majority of groups favored locations for wind turbines within existing industrial areas rather than in agricultural areas in order to preserve the more natural land. Five groups earmarked a cluster of wind turbines in the industrial area of Twence in the west of Enschede and, similarly, 4 groups located wind turbines within the industrial area of Maarsteden. Additionally, 4 of the 8 groups located some wind turbines close to the recreation area Het Ruitbeek in the south of Enschede. In terms of solar rooftops, the main conclusions from the mapping sessions were to use, predominantly and where possible, industrial buildings rather than private housing because of higher efficiency; and to engage with the local housing cooperative for setting up solar, because it owns a large amount of the apartment housing in Enschede.

Other general statements derived from the workshop sessions stated that, in principle, the majority of the participants preferred solar options over wind because of the lower visual impact on the landscape; while some other participants acknowledge, based on the outcomes of the mapping sessions, that a combination of both is the most logical option. Agreement exists among the participants that the municipality should promote participation in the projects that move forward.

\subsection{Lessons Learned}

The analysis of the lessons learned by the participants in the sense of social learning is essentially derived from the recordings of the group discussions during the mapping sessions. One major lesson the participants learned from the workshop sessions was that it is almost impossible to achieve the goals within single neighborhoods and based purely on solar rooftops. They also learned that using solar panels to fill single locations within Enschede, that have already been the subject of lengthy discussions, such as the airport or the Usseler Ess, would not be enough to achieve the targets. Likewise, a solution such as that favored by many groups of putting solar panels along the highways provides only a very small amount of the overall energy needed. Additional issues that were discussed showed that while big roofs are potentially more efficient for setting up solar panels, many roofs are simply not strong enough to hold the necessary construction.

With respect to the implementation of wind turbines, participants learned that a single turbine may provide a significantly higher amount of renewable energy compared to installations of solar rooftops but also compared to the same space covered with solar farms. However, in this context, some participants remarked on the much stronger visual impact of the wind turbines on the landscape, as they can be seen from far away. In summary, the main conclusion derived from the workshops for many participants was that a mix of solar and wind is the most logical option in order to achieve the renewable-energy goals set by the municipality.

Having said this, it became obvious that the choice of locations is crucial while working on achieving the energy goals. Here the COLLAGE tool was perceived as very positive by the overwhelming number of participants. Various forms of social learning were reported by the participants (Figure 6). More than $85 \%$ of all participants stated that the session helped them to get to know the views of others on renewable energy. More than $80 \%$ agreed that they were able to 
share their views on renewable energy with the other participants during the workshops. Finally, almost $75 \%$ claimed that they had learned something about renewable energy during the workshop.

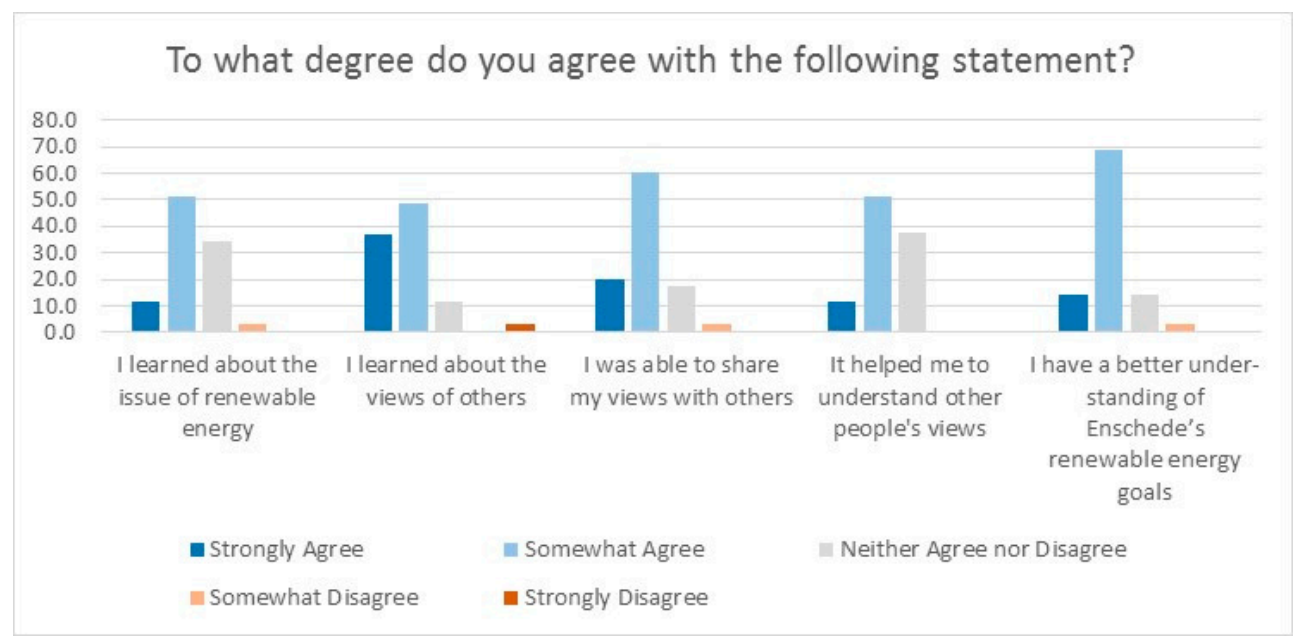

Figure 6. Lessons learnt by the participants.

The main added value of the tool as seen by the participants was that it allows better communication $(27.1 \%)$ and that it helps to obtain more informed results $(33.3 \%)$. Regarding the usability of the tool (Figure 7), the majority of participants claimed that the COLLAGE tools were transparent (74.3\% of agreement along participants), user friendly (62.9\% agreement), and provided a good level of detail $(60 \%)$. In addition, the level of guidance provided by the mediator and the chauffeur during the mapping session was perceived as positive by the overwhelming majority $(91 \%)$.

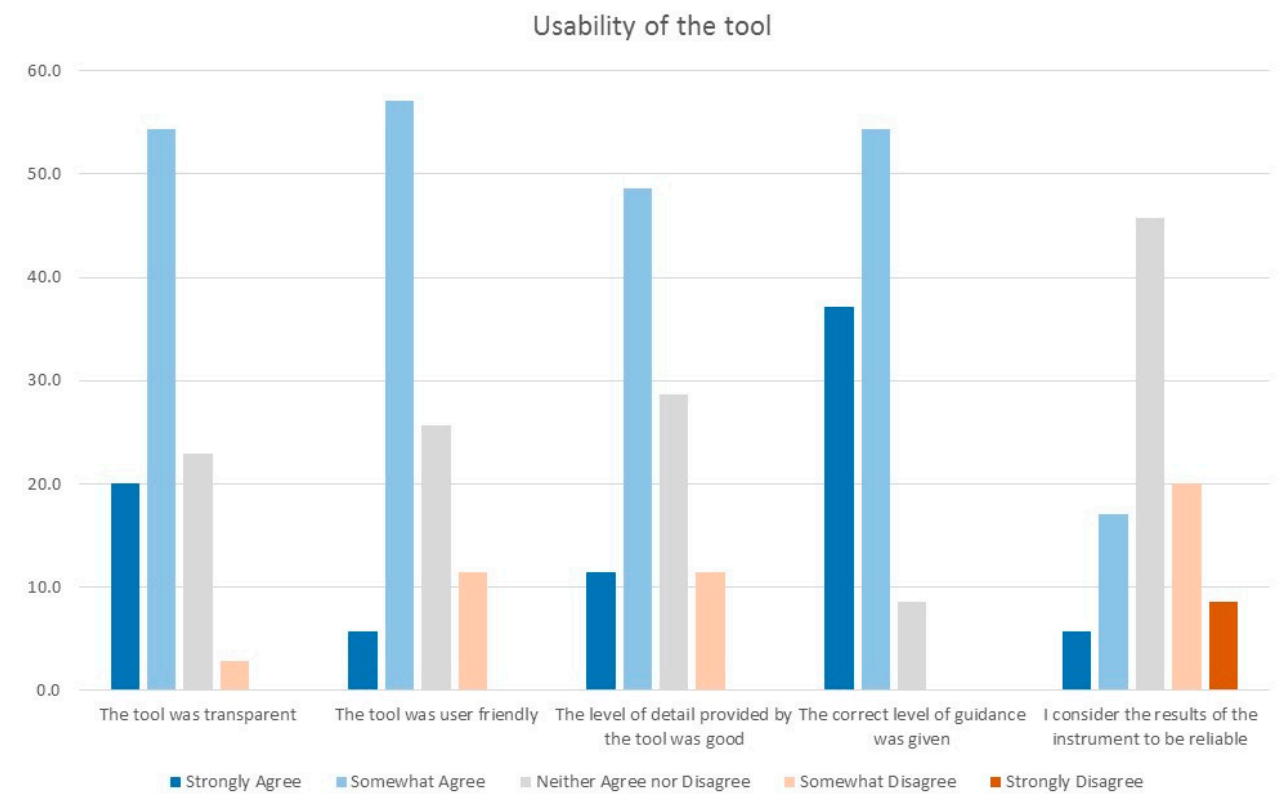

Figure 7. Usability of the COLLAGE tool.

The results of the tool, however, were not perceived as reliable by about $30 \%$ of the participants (Figure 7, final item on the right). This somewhat surprising finding refers mainly to the mapping results on the tables, as can be seen from a number of comments the participants made during the mapping sessions and in response to the open-ended questions in the questionnaire. The main issues 
mentioned with respect to limited reliability were that the tool should also include other types of renewable-energy sources such as biogas, geothermal energy or hydropower in order to be more realistic and, therefore, reliable; and that the role of storage of energy is unclear and also needs to be considered. Moreover, a few participants claimed that, given the limited options for renewable energy available in Enschede (see above), this type of trade-off process should be carried out at the national level given that there are more options available.

In summary, we can conclude that the majority of participants perceived the COLLAGE tool and workshop sessions to be very useful for understanding and learning about requirements, options, and limitations of renewable energy in general as well as for Enschede specifically. On the other hand, the mapping results were perceived as less valuable and reliable, although the process of collaborative mapping was essential for achieving the envisaged goals of social learning about renewable energy.

\section{Discussion and Conclusions}

Rogers et al. [34] found, for the UK, that "community-based renewable-energy projects, with high levels of public participation, are more likely to be accepted by the public than top-down development of large-scale schemes". Other authors $([11,12,14]$ stress the importance of local governments for a successful transition to renewable-energy sources. Taking both arguments together, it becomes obvious from the empirical results obtained during the workshops in Enschede that the COLLAGE tool can be an important building block towards a new local energy governance [19], helping to overcome known barriers of community-related social acceptance as identified by Sovacool and Lakshmi Ratan [8]. Checking against the authors' framework (see Section 1): the COLLAGE tool helps to involve people and communities in the decision to site or permit renewable-energy facilities; and it helps to make community members aware of the benefits of, but also the requirements for, renewable energy by disclosing the spatial consequences of overall municipal goals.

\subsection{Added Value of the COLLAGE for Engaging with Communities in Renewable-Energy Planning}

The COLLAGE tool serves a public dialogue that addresses systematic aspects of future energy systems by providing what Devine-Wright [10] calls "a basis for creating a social contract on technical change". The interactive nature of the tool allows users to explore the consequences of various renewable-energy technologies and the mix of energy sources. In that sense it allows flexibility in experiencing how to achieve a given goal [35]. The spatial approach of the tool, with the flexibility to zoom into various locations, allows citizens to demarcate place-related identities, which often leads to oppositional behavior [10] if they are not considered while siting renewable-energy projects.

Several participants stated at the end of the workshops that they had learned quite a lot about the benefits of renewable energy. They were involved in a general discussion of locations, which could also serve as a basis for further involvement in concrete siting decisions of single renewable-energy projects. Participants indicated that they had gained a better understanding of what it meant for Enschede, and were consequently more willing to accept renewable-energy projects.

An interesting finding is that the participants in the workshops were obviously more ambitious in defining goals for renewable-energy production in Enschede than the city administration was in its sustainability strategy [28], which was based on a study of technical feasibility with respect to renewable energy [30]. The average goal of the workshop participants of 33\% from renewable energy (see above) is based on a total of only 35 participants, and is therefore clearly not representative for the city of Enschede as a whole. However, it should be emphasized that it was far from the case that only pro-renewable energy citizens participated, as the participants also included citizens who were critical of renewable energy. In addition, the mapping results show that the majority of participants were able to envisage the allocation of more space for renewable energy than that which is needed to achieve the $12 \%$ goal in 2030 . One can conclude that conducting such citizen workshops using the COLLAGE tool prior to developing a local renewable-energy strategy or setting particular goals might be a useful 
addition to the usual studies, surveys, or information campaigns, in order to better capture and reflect citizens' perceptions and ideas.

If this approach is taken, stakeholders as well citizens can be involved from the early phase of local energy planning onwards, not merely looking at single project sites but developing an overall city strategy. In the case of the city of Enschede, the workshops' results, as well as the outcomes and findings of other activities conducted during the Enschede wekt op campaign, were summarized in a policy document for the entire city [32]. Based on such a renewable-energy strategy, potential co-operations for single locations or projects might be identified involving local actors as well as potential investors and developers to jointly develop so-called community renewable-energy projects [36]. Walker et al. [37] found, for the UK, that mutual trust between investors and developers of renewable-energy projects and local communities is a crucial prerequisite for a successful implementation of renewable-energy projects. Moreover, mechanisms are needed for partner identification at an early stage and within a stable and supportive policy context [38]. Interactive workshops involving all three groups could serve as a suitable mechanism for achieving such requirements.

\subsection{Limitations of the COLLAGE Tool and Workshops}

A limitation of the model in its current form that became apparent during the workshops is that the participants often focused during the mapping sessions more on achieving the given goals in terms of renewable-energy production than on a critical and eventually conflicting discussion of potential locations for renewable-energy installations. Rather than discussing each single location in detail, it could be observed that some locations were mapped without much discussion in order to reach a certain amount of renewable energy. In the context of serious gaming, Harteveld et al. [39] describe this as the reflection dilemma that occurs when players, in our case the participants, forget the real world and focus on the world that is unravelling on the screen, i.e., the maptable, and this immersion detracts from the potential meaning. A potential way to overcome or at least mitigate this in the COLLAGE model would be to add other indicators to the model, particularly those that do not count only benefits, such as renewable energy produced, but also costs, such as loss of natural area, or other environmental impacts caused by the interventions. A cost-benefit calculation could also be a valuable add-on. If more trade-offs become visible, it will lead in turn to more serious interactions, discussions and mapping activities.

Another limitation of the model is that it can only host a limited number of participants, i.e., large-group participation would not be possible using the model. More maptables could be used to serve larger groups of participants, but that would also require more moderation, facilitation and technical support. Alternatively, the COLLAGE model could be applied in an analogue modus with participants working on large-scale paper maps and placing solar farms and wind turbines onto the map by means of Lego bricks and pawns from a board game. In doing so, potentially larger groups of participants could be involved. With such an analogue COLLAGE approach, the digital divide between different age groups in terms of computer and communication technology literacy could be addressed. In our workshops, we observed that younger participants were on average much faster at learning and applying the COLLAGE tool than the significantly older participants. However, the downside of such an analogue COLLAGE approach would be that all the advantages resulting from the digital approach would be lost, such as zooming into locations on the interactive maptable and the on-the-fly calculation of outcome indicators. Consequently, the goals of analogue COLLAGE workshops would have to be adapted.

Finally, one limitation that became obvious during the mapping sessions was the lack of data included in the model. An obviously useful layer of information would be to know which buildings are constructed in a manner suitable for solar rooftops and which are not. Other layers of data and information that could be added to improve the model would be the spatially different wind capacity or the quality or fertility of the soil on the agricultural land. This would enable a better assessment 
of how much wind can be harvested where and at what cost, hence addressing a further trade-off in addition to those discussed above.

The analysis of workshop results could have benefitted if the participants had been interviewed prior to the workshop as well as afterwards. This was not possible for logistical reasons, as the participants were not asked to give their email addresses while registering for the workshops. With such information, changes in attitudes towards renewable energy could have been attributed much more clearly to the COLLAGE tool and workshop. However, it should be recognized that citizens' environmental positions and attitudes only change slowly and over long periods of time, but not necessarily within a two-hour workshop. We can conclude that stakeholders as well as citizens should ideally be involved in a series of workshops with the COLLAGE tool; not only to fully understand and utilize the benefits of the tool, but also in order to contribute to the concrete development and roll out of the tool for a specific location and context in the sense of a participatory, stakeholder-based modelling process [40] that helps increase the quality, and thereby legitimacy, of the models as well as triggering collaborative learning effects.

\subsection{Further Research Needs}

There is a general consensus among scholars that, in order to increase the implementation of renewable-energy projects for combatting climate change, an improved engagement and participation of the public and stakeholders needs to be achieved $[10,11]$. In this paper we describe the COLLAGE tool that is designed for involving stakeholders in the participatory mapping of renewable-energy locations. Using the city of Enschede in The Netherlands, where we conducted stakeholder workshops for locating wind turbines and solar panels, we have shown that the model helps to increase awareness for renewable energy and triggers social learning about renewable energy among the local stakeholders and citizens.

To fully support local energy governance [19], the tool would need to be extended to include other types of renewable energy. While in Enschede wind and solar are the dominant forms of renewable energy, biogas or geothermal energy can also be elements of a renewable-energy strategy in other cities and countries. Moreover, other outcome indicators resulting from the various allocations of renewable-energy projects and indicating varying impacts, cost and benefits, thereby illustrating potential trade-offs, would need to be added to the model.

In order to enhance the usability of the COLLAGE tool, a potentially useful addition might be to add a 3D visualization on the second screen to the 2D map on the maptable, as not all participants are able to read 2D maps well. Hettinga [41] discussed that when presenting information on renewable-energy measures to be implemented in a 3D environment that is recognizable as their own neighbourhood, participants can better relate the information presented to this environment. In particular, the aesthetic impact of wind turbines on the landscape could be visualized more clearly in a 3D environment.

Acknowledgments: The authors would like to thank the city of Enschede for funding the workshops and providing data, and particularly Ed van't Erve, Hanneke Spoler, Henk Visser and Benny Schulte Lubberink from the city of Enschede for participating in the development of the COLLAGE model and tool. We also thank the citizens of Enschede for actively participating in the workshops. Thanks also goes to Frans van den Bosch, Christian Kempf, Rehana Shrestha, Carissa Champlin, and Inge Kaarbat for helping with the implementation of the workshops; Johannes Flacke thanks Heike Köckler for providing useful comments on a draft version of the paper; and Juliet Wilson for careful proofreading of the manuscript. We thank the anonymous reviewers for providing useful comments in order to improve the paper. Finally, we thank the PGM department of ITC/UT, particular our colleagues and students who participated in the test workshops and thereby helped in developing the COLLAGE tool.

Author Contributions: Cheryl de Boer and Johannes Flacke jointly initiated the study, conceptualized the COLLAGE model and tool and conducted the workshops. Johannes Flacke developed and implemented the COLLAGE tool, analyzed the spatial and statistical results, facilitated the workshop session and wrote the text. Cheryl de Boer moderated the workshops and contributed to the analysis of the workshop results.

Conflicts of Interest: The authors declare no conflict of interest. 


\section{Appendix A}

\section{Questionnaire}

This survey is part of a workshop on renewable energy in Enschede. Your participation will be a great help to us. The responses will be kept anonymous. They will be used to gain a better understanding of the participants' perception of renewable energy in Enschede and the usability of the tools used in the workshop. In addition, summarized data will be provided to the Municipality of Enschede to use to evaluate the workshop session. Please complete this survey before you leave tonight.

Thank you for your participation!

\section{Part 1: Renewable Energy for Enschede}

1. Your general perception of renewable energy. How much do you agree with the following statements?

\begin{tabular}{llllll}
\hline & $\begin{array}{l}\text { Strongly } \\
\text { Agree }\end{array}$ & $\begin{array}{l}\text { Somewhat } \\
\text { Agree }\end{array}$ & $\begin{array}{l}\text { Neither } \\
\text { Agree nor } \\
\text { Disagree }\end{array}$ & $\begin{array}{l}\text { Somewhat } \\
\text { Disagree }\end{array}$ & $\begin{array}{l}\text { Strongly } \\
\text { Disagree }\end{array}$ \\
\hline $\mathbf{1} \quad \begin{array}{l}\text { Renewable energy is a good option } \\
\text { to reduce GHG emissions }\end{array}$ & $\square$ & $\square$ & $\square$ & $\square$ \\
\hline $\mathbf{2} \quad \begin{array}{l}\text { Renewable energy helps to reduce } \\
\text { my energy costs }\end{array}$ & $\square$ & $\square$ & $\square$ & $\square$ & $\square$ \\
\hline $\mathbf{3} \quad \begin{array}{l}\text { Renewable energy is good for the } \\
\text { Enschede economy }\end{array}$ & $\square$ & $\square$ & $\square$ & $\square$ \\
\hline $\mathbf{4} \quad \begin{array}{l}\text { Renewable energy helps secure } \\
\text { energy supply for the future }\end{array}$ & $\square$ & $\square$ & $\square$ & $\square$ \\
\hline $\mathbf{5} \quad \begin{array}{l}\text { The costs and benefits of renewable } \\
\text { energy should be kept local }\end{array}$ & $\square$ & $\square$ & $\square$ & $\square$ \\
\hline
\end{tabular}

2. The total energy consumption of Enschede is predicted to be $3.000 .000 \mathrm{MWh}$ in 2030 . How much do you think Enschede should plan to produce itself with renewable energy (on a scale from 0-100\%)

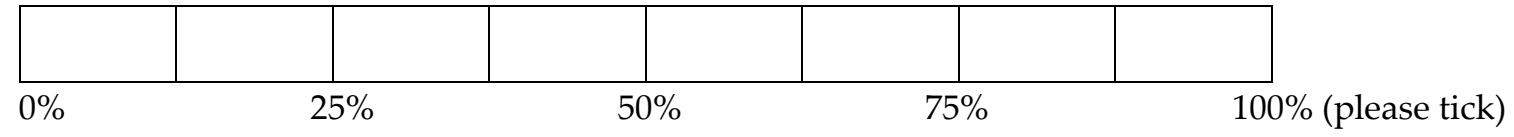

3. What is your opinion on the following renewable energy sources for Enschede?

\begin{tabular}{llllll}
\hline & $\begin{array}{l}\text { Strongly } \\
\text { Support }\end{array}$ & $\begin{array}{l}\text { Somewhat } \\
\text { Support }\end{array}$ & $\begin{array}{l}\text { Neither Support } \\
\text { nor Oppose }\end{array}$ & $\begin{array}{l}\text { Rather } \\
\text { Oppose }\end{array}$ & $\begin{array}{l}\text { Strongly } \\
\text { Oppose }\end{array}$ \\
\hline $\mathbf{1}$ Wind energy & $\square$ & $\square$ & $\square$ & $\square$ & $\square$ \\
\hline $\mathbf{2}$ Solar energy & $\square$ & $\square$ & $\square$ & $\square$ & $\square$ \\
\hline $3 \quad$ Geothermal & $\square$ & $\square$ & $\square$ & $\square$ & $\square$ \\
\hline $\mathbf{4}$ Biomass & $\square$ & $\square$ & $\square$ & $\square$ & $\square$ \\
\hline $\mathbf{5}$ Other: & $\square$ & $\square$ & $\square$ & $\square$ & $\square$ \\
\hline
\end{tabular}

4. Do you have any renewable energy systems installed in your house in Enschede already?

Yes $\square$ no

If yes, what kind: 
Part 2: The renewable energy workshop and the maptable tool

1. What do you consider to be the most important value of the tool (select one)

$\square$ better communication $\square$ better cooperation $\square$ more efficient work $\square$ more informed result $\square$ none $\square$ Other, namely

2. To what degree do you agree with the following statement?

\begin{tabular}{lllllll}
\hline & $\begin{array}{l}\text { Strongly } \\
\text { Agree }\end{array}$ & $\begin{array}{l}\text { Somewhat } \\
\text { Agree }\end{array}$ & $\begin{array}{l}\text { Neither } \\
\text { Agree nor } \\
\text { Disagree }\end{array}$ & $\begin{array}{l}\text { Somewhat } \\
\text { Disagree }\end{array}$ & $\begin{array}{l}\text { Strongly } \\
\text { Disagree }\end{array}$ & $\begin{array}{l}\text { Don't } \\
\text { Know/na }\end{array}$ \\
\hline $\mathbf{1} \begin{array}{l}\text { I learned about the issue } \\
\text { of renewable energy }\end{array}$ & $\square$ & $\square$ & $\square$ & $\square$ & $\square$ & $\square$ \\
\hline $\mathbf{2} \begin{array}{l}\text { I learned about the views } \\
\text { of others }\end{array}$ & $\square$ & $\square$ & $\square$ & $\square$ & $\square$ & $\square$ \\
\hline $\mathbf{3} \begin{array}{l}\text { I was able to share my } \\
\text { views with others }\end{array}$ & $\square$ & $\square$ & $\square$ & $\square$ & $\square$ & $\square$ \\
\hline $\begin{array}{l}\text { It helped me to } \\
\text { understand other } \\
\text { people's views }\end{array}$ & $\square$ & $\square$ & $\square$ & $\square$ & $\square$ & $\square$ \\
\hline $\begin{array}{l}\text { I have a better } \\
\text { understanding of } \\
\text { Enschede's energy goals }\end{array}$ & $\square$ & $\square$ & $\square$ & $\square$ & $\square$ & $\square$ \\
\hline
\end{tabular}

3. Questions on usability of the tool

\begin{tabular}{lllllll}
\hline & $\begin{array}{l}\text { Strongly } \\
\text { Agree }\end{array}$ & $\begin{array}{l}\text { Somewhat } \\
\text { Agree }\end{array}$ & $\begin{array}{l}\text { Neither } \\
\text { Agree nor } \\
\text { Disagree }\end{array}$ & $\begin{array}{l}\text { Somewhat } \\
\text { Disagree }\end{array}$ & $\begin{array}{l}\text { Strongly } \\
\text { Disagree }\end{array}$ & $\begin{array}{l}\text { Don't } \\
\text { Know/na }\end{array}$ \\
\hline $\mathbf{1} \quad$ The tool was transparent & $\square$ & $\square$ & $\square$ & $\square$ & $\square$ & $\square$ \\
\hline $\mathbf{2} \quad$ The tool was user friendly & $\square$ & $\square$ & $\square$ & $\square$ & $\square$ & $\square$ \\
\hline $\mathbf{3} \begin{array}{l}\text { The level of detail provided } \\
\text { by the tool was good }\end{array}$ & $\square$ & $\square$ & $\square$ & $\square$ & $\square$ & $\square$ \\
\hline $\mathbf{4} \begin{array}{l}\text { The correct level of guidance } \\
\text { was given }\end{array}$ & $\square$ & $\square$ & $\square$ & $\square$ & $\square$ & $\square$ \\
\hline $\mathbf{5} \begin{array}{l}\text { I consider the results of the } \\
\text { instrument to be reliable }\end{array}$ & $\square$ & $\square$ & $\square$ & $\square$ & $\square$ & $\square$ \\
\hline
\end{tabular}

4. What was the most important thing that you learned during the workshop?

5. Please provide any general comments about the workshop or the computer tool below. (optional) 


\section{Part 3: About you}

1. Age group: $\square<18$ years $\square$ 18-30 years $\square$ 31-50 years $\square 51-65$ years $\square>65$ years

2. Where do you live in Enschede? $\square$ Centrum $\square$ Noord $\square$ Oost $\square$ West $\square$ Zuid $\square$ not in Enschede

3. What kind of property do you live in? $\square$ own house $\square$ rented house $\square$ flat/apartment $\square$ Other [Please explain:

4. What was the average gross monthly income of your household in the last year (in euros)?

$\square<1.000 \square 1.001-1.999 \square 2.000-2.999 \square 3.000-3.999 \square>=4000$

\section{References}

1. United Nations Framework Convention on Climate Change (UNFCC). Adoption of the Paris Agreement; UNFCC: Paris, France, 2015.

2. European Commission. The Roadmap for Transforming the EU into a Competitive, Low-Carbon Economy by 2050; European Commission: Brussels, Belgium, 2012.

3. Reckien, D.; Flacke, J.; Dawson, R.J.; Heidrich, O.; Olazabal, M.; Foley, A.; Hamann, J.J.-P.; Orru, H.; Salvia, M.; Gregorio Hurtado, S.; et al. Climate change response in Europe: What's the reality? Analysis of adaptation and mitigation plans from 200 urban areas in 11 countries. Clim. Chang. 2014, 122, 331-340. [CrossRef]

4. Eurostat. Renewable Energy Statistics. Available online: http://ec.europa.eu/eurostat/statistics-explained/ index.php/Renewable_energy_statistics (accessed on 17 July 2017).

5. Breukers, S.; Wolsink, M. Wind energy policies in The Netherlands: Institutional capacity-building for ecological modernisation. Environ. Politics 2007, 16, 92-112. [CrossRef]

6. Devine, W.P. Renewable Energy and the Public: From NIMBY to Participation; Earthscan: Milton Park, UK, 2011.

7. Wüstenhagen, R.; Wolsink, M.; Bürer, M.J. Social acceptance of renewable energy innovation: An introduction to the concept. Energy Policy 2007, 35, 2683-2691. [CrossRef]

8. Sovacool, B.K.; Lakshmi Ratan, P. Conceptualizing the acceptance of wind and solar electricity. Renew. Sustain. Energy Rev. 2012, 16, 5268-5279. [CrossRef]

9. Devine-Wright, P.; Batel, S.; Aas, O.; Sovacool, B.; Labelle, M.C.; Ruud, A. A conceptual framework for understanding the social acceptance of energy infrastructure: Insights from energy storage. Energy Policy 2017, 107, 27-31. [CrossRef]

10. Devine-Wright, P. Public engagement with large-scale renewable energy technologies: Breaking the cycle of NIMBYism. WIREs Clim. Chang. 2011, 2, 19-26. [CrossRef]

11. Breukers, S.; Wolsink, M. Wind power implementation in changing institutional landscapes: An international comparison. Energy Policy 2007, 35, 2737-2750. [CrossRef]

12. Fudge, S.; Peters, M.; Woodman, B. Local authorities as niche actors: The case of energy governance in the UK. Environ. Innov. Soc. Transit. 2016, 18, 1-17. [CrossRef]

13. International Energy Agency (IEA). Cities, Towns \& Renewable Energy: Yes In My Front Yard; IEA: Paris, France, 2009.

14. Mey, F.; Diesendorf, M.; MacGill, I. Can local government play a greater role for community renewable energy? A case study from Australia. Energy Res. Soc. Sci. 2016, 21, 33-43. [CrossRef]

15. Rittel, H.; Webber, M. Dilemmas in a general theorie of planning. Policy Sci. 1973, 4, 155-169. [CrossRef]

16. Head, B. Wicked Problems in Public Policy. Public Policy 2008, 3, 101-118.

17. Xiang, W.-N. Working with wicked problems in socio-ecological systems: Awareness, acceptance, and adaptation. Landsc. Urban Plan. 2013, 110, 1-4. [CrossRef]

18. Armitage, D.; Marschke, M.; Plummer, R. Adaptive co-management and the paradox of learning. Glob. Environ. Chang. 2008, 18, 86-98. [CrossRef]

19. Parag, Y.; Hamilton, J.; White, V.; Hogan, B. Network approach for local and community governance of energy: The case of Oxfordshire. Energy Policy 2013, 62, 1064-1077. [CrossRef]

20. Rogers, Y.; Lindley, S. Collaborating around vertical and horizontal large interactive displays: Which way is best? Interact. Comput. 2004, 16, 1133-1152. [CrossRef]

21. CommunityViz Software. Available online: http://communityviz.city-explained.com/communityviz/ index.html (accessed on 17 July 2017). 
22. Pelzer, P.; Geertman, S. Planning support systems and interdisciplinary learning. Plan. Theory Pract. 2014, 15, 527-542. [CrossRef]

23. Pelzer, P.; Geertman, S.; van der Heijden, R. A comparison of the perceived added value of PSS applications in group settings. Comput. Environ. Urban Syst. 2016, 56, 25-35. [CrossRef]

24. Shrestha, R.; Koeckler, H.; Flacke, J.; Martínez, J.A.; van Maarseveen, M. Interactive knowledge co-production and integration for healthy urban development. Sustainability 2017, under review.

25. Zonnekaart. Available online: https:/ / www.mapgear.nl/web/zonnekaart.html (accessed on 17 July 2017).

26. Aerial Photographs (Luchtfoto). Available online: https://geodata.nationaalgeoregister.nl/tiles/service/ wmts/lufolabels? (accessed on 18 October 2017).

27. Street Names, Regions, Districts (Luchtfoto Lables). Available online: https:/ / geodata.nationaalgeoregister. $\mathrm{nl} /$ tiles/service/wmts/lufolabels? (accessed on 18 October 2017).

28. Available online: https://www.enschede.nl/sites/default/files/actieplan-duurzaamheid.pdf (accessed on 19 October 2017).

29. Energie in Beeld. Available online: http:/ / www.energieinbeeld.nl/ (accessed on 17 July 2017).

30. Energieonderzoek Centrum Nederland (ECN). Nationale Energieverkenning 2016; ECN Policy Studies: Amsterdam, The Netherlands, 2016.

31. Enschede Wekt Op. Available online: http:/ / enschedewektop.nl/ (accessed on 17 July 2017).

32. Available online: https://www.enschede.nl/enschede-wekt-op-vertaald-naar-raadsvoorstel (accessed on 19 October 2017).

33. Pelzer, P.; Goodspeed, R.; Brömmelstroet, M.T. Facilitating PSS Workshops: A Conceptual Framework and Findings from Interviews with Facilitators. In Planning Support Systems and Smart Cities; Geertman, S., Ferreira, J., Goodspeed, R., Stillwell, J., Eds.; Springer: Heidelberg, Germany, 2015; pp. 355-369.

34. Rogers, J.; Simmons, E.; Convery, I.; Weatherall, A. Public perceptions of opportunities for community-based renewable energy projects. Energy Policy 2008, 36, 4217-4226. [CrossRef]

35. Barry, J.; Ellis, G. Beyond consensus? Agonism, republicanism and a low carbon future. In Renewable Energy and the Public: From NIMBY to Participation; Devine, W.P., Ed.; Earthscan: Milton Park, UK, 2011; pp. $29-42$.

36. Walker, G.; Devine-Wright, P. Community renewable energy: What should it mean? Energy Policy 2008, 36, 497-500. [CrossRef]

37. Walker, G.; Devine-Wright, P.; Hunter, S.; High, H.; Evans, B. Trust and community: Exploring the meanings, contexts and dynamics of community renewable energy. Energy Policy 2010, 38, 2655-2663. [CrossRef]

38. Goedkoop, F.; Devine-Wright, P. Partnership or placation? The role of trust and justice in the shared ownership of renewable energy projects. Energy Res. Soc. Sci. 2016, 17, 135-146. [CrossRef]

39. Harteveld, C.; Guimaraes, R.; Mayer, I.S.; Bidarra, R. Balancing Play, Meaning and Reality: The Design Philosophy of LEVEE PATROLLER. Simul. Gaming 2010, 41, 316-340. [CrossRef]

40. Voinov, A.; Bousquet, F. Modelling with stakeholders: Position paper. Environ. Model. Softw. 2010, 25, 1268-1281. [CrossRef]

41. Hettinga, S. Using a 3D Serious Game to Involve Citizens in Renewable Energy Transition Management; University of Twente: Enschede, The Netherlands, 2016.

(C) 2017 by the authors. Licensee MDPI, Basel, Switzerland. This article is an open access article distributed under the terms and conditions of the Creative Commons Attribution (CC BY) license (http:// creativecommons.org/licenses/by/4.0/). 